\title{
Expression of Adiponectin Receptor 1 Is Indicative of Favorable Prognosis in Non-small Cell Lung Carcinoma
}

\author{
Jamshid Abdul-Ghafar, ${ }^{1}$ Sung Soo Oh, ${ }^{2}$ Sun-Mi Park, ${ }^{1}$ Peninah Wairagu, ${ }^{3}$ \\ Shun Nyung Lee, ${ }^{4}$ Yangsik Jeong, ${ }^{3}$ Minseob Eom, ${ }^{1}$ Suk-Joong Yong ${ }^{4}$ and \\ Soon-Hee Jung ${ }^{1}$

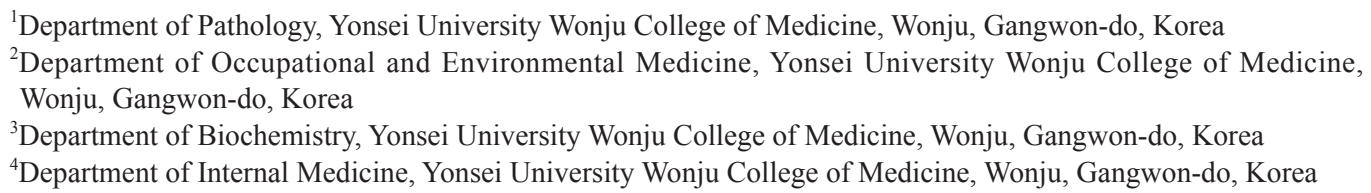

Lung cancer is a major cause of cancer-related death worldwide. It is believed that obesity-related malignancies such as breast, endometrial, colorectal, and kidney carcinomas have lower plasma level and/ or tissue expression of adiponectin receptors. However, the association between adiponectin receptors and lung cancer, a non obesity-related malignancy, is still unknown. We evaluated the tissue expression of adiponectin receptor (AdipoR) 1 and AdipoR2 in 83 cases of non-small cell lung carcinoma (NSCLC) and matched non-neoplastic lung tissues by immunohistochemistry and real-time polymerase chain reaction (PCR). Clinicopathological data, including smoking history, smoker's bronchiolitis, emphysema, lymph node metastasis, and T-stage were collected and evaluated. Expression of immunohistochemically stained AdipoR1 and AdipoR2 was observed in all samples of non-neoplastic lung tissues. Both receptors showed higher mRNA expression in non-neoplastic than neoplastic tissues $(p<0.05)$. In NSCLC tissues, AdipoR1 immunohistochemical expression was not observed in most of patients with squamous cell carcinoma and current smoking history (31/42, $p=0.04$ and 25/29, $p=0.003$, respectively). Additionally, AdipoR1 mRNA expression was significantly lower in patients with lymph node metastasis $(p=0.05)$. Meanwhile, AdipoR2 immunohistochemical stain expression was inversely correlated with T-stage $(p=0.05)$ and AdipoR2 mRNA expression was significantly lower in patients with smoker's bronchiolitis $(p=0.01)$ and emphysema $(p=0.03)$. Patients with expression of AdipoR1 had longer overall survival. AdipoR2 expression was not correlated with patients' survival. In conclusion, we suggest that expression of AdipoR1 is indicative of favorable prognosis and may be used as prognostic marker in NSCLC.

Keywords: adiponectin receptor; immunohistochemistry; mRNA; non-small cell lung carcinoma; polymerase chain reaction

Tohoku J. Exp. Med., 2013 Feb, 229 (2), 153-162. (C) 2013 Tohoku University Medical Press

Adipose tissue is now considered to function as an endocrine organ that plays an important role in integrating metabolic and inflammatory signals with the endocrine system (Chandran et al. 2003). Adipose tissue secretes leptin, tumor necrosis factor (TNF)- $\alpha$, angiotensinogen, plasminogen activator inhibitor 1 (PAI-1), adipsin, resistin, and adiponectin (Chandran et al. 2003).

Adiponectin is a 244 amino-acid peptide hormone whose gene is located on chromosome 3q27 (Chandran et al. 2003). By binding to its two active receptors, -adiponectin receptor 1 (AdipoR1) and adiponectin receptor 2 (AdipoR2)- on target tissues, adiponectin is believed to link obesity, insulin resistance, and diabetes (Chandran et al.
2003; Ishikawa et al. 2007).

Circulating plasma levels of adiponectin have been reported to be inversely correlated with body mass index (BMI) and conditions related to insulin resistance such as visceral obesity and type 2 diabetes (Ishikawa et al. 2007). Therefore, there has been great interest in determining whether adiponectin has a protective role in carcinogenesis (Kelesidis et al. 2006; Byeon et al. 2010). Adiponectin has anti-angiogenic (Molica et al. 2009), anti-proliferative (Dos Santos et al. 2008; Benaitreau et al. 2009), and proapoptotic effects, and also arrests cancer cell growth (Kang et al. 2005; Cong et al. 2007), having both direct effects on carcinogenesis and indirect effects through alteration of hor-

Received September 11, 2012; accepted January 7, 2013. Published online January 26 2013; doi: 10.1620/tjem.229.153.

Correspondence: Soon-Hee Jung, M.D., Ph.D., Department of Pathology, Yonsei University Wonju College of Medicine, \#162 Ilsan-dong, Wonju, Gangwon-do 220-701, Korea.

e-mail: soonheej@yonsei.ac.kr 
mones and cytokine levels (Kelesidis et al. 2006).

Recent studies have shown an association between low plasma levels and/or tissue expression of adiponectin, along with an increased risk of various malignancies for which there is an established association with increased body weight and/or insulin resistance including breast (Miyoshi et al. 2003; Mantzoros et al. 2004), endometrial (Petridou et al. 2003; Cust et al. 2007), colorectal (Wei et al. 2005; Yoneda et al. 2008; Barresi et al. 2009; Byeon et al. 2010; Gonullu et al. 2010), renal (Spyridopoulos et al. 2007), and prostate (Mistry et al. 2006) cancers, as well as leukemia (Molica et al. 2009).

Furthermore, studies on breast and prostate cancer cell lines have shown that adiponectin may control cancer cell numbers by inhibiting cell proliferation and inducing apoptosis (Bub et al. 2006; Dieudonne et al. 2006), which suggests that adiponectin may suppress cancer cell development.

The association between adiponectin and lung cancer, a non-obesity-related malignancy, has not been explored in detail. Functional adiponectin receptors are normally expressed in lung epithelial cells (Miller et al. 2009). However, the tissue expression of AdipoR1 and AdipoR2 and their correlation with lung carcinoma remains controversial.

Smoking is a major health problem and a risk factor for the majority of lung cancers (Jemal et al. 2006). Smokers have a lower plasma level of adiponectin than non-smokers (Takefuji et al. 2007; Otsuka et al. 2009; Sull et al. 2009; Kawamoto et al. 2010). It is not yet clear whether the lower plasma level of adiponectin in lung cancers is a result of smoking or due to the coexistence of insulin resistance and lung cancer.

Alcohol has been shown to directly inhibit the production of adiponectin from adipose tissue; the serum level of adiponectin was significantly lower in heavy drinkers than in light or moderate drinkers (de Oliveira et al. 2012; Hamano et al. 2012; Makita et al. 2012). However, evidence shows that light or moderate alcohol consumption does increase adiponectin levels (Sierksma et al. 2004).

In addition, thiazolidinediones (TZDs), a class of antidiabetic drugs, have been shown to act as anti-cancer agents (Govindarajan et al. 2007; Blanquicett et al. 2008; Yoshizaki et al. 2010). TZDs are synthetic ligands for peroxisome proliferator-activated receptor (PPAR)- $\gamma$. They activate the adiponectin system and increase the plasma levels of this hormone (Govindarajan et al. 2007; Petridou et al. 2007). In a recently published retrospective study, the risk of lung cancer among diabetic patients who took TZD as an antidiabetic drug was 33\% lower than that of diabetic patients who were not on a TZD regimen (Govindarajan et al. 2007). The above findings suggest that changes in adiponectin levels and/or tissue expression of AdipoR1 and AdipoR2 could be related to the development of lung carcinoma.

In this study, we investigated the relationship between expression of AdipoR1 and AdipoR2 and non-small cell lung carcinoma (NSCLC), a malignancy unrelated to obesity or insulin resistance. Furthermore, we investigated changes of protein and mRNA levels according to the clinicopathological parameters.

\section{Materials and Methods}

Study population

Hematoxylin and eosin slides of NSCLC specimens surgically resected between 2006 and 2010 in Wonju Christian Hospital, Yonsei University were reviewed by two expert pathologists. Eighty-three cases consisting of 41 adenocarcinomas and 42 squamous cell carcinomas were selected out of 150 cases. The selection was based on the availability of adequate neoplastic tissue within the paraffin blocks, absence of necrosis and availability of patient records containing patient history and follow-up information. The following were recorded for each case: age, gender, BMI, smoking status, alcohol consumption level, treatment history, status of lymph node, histological tumor subtype, and pathological tumor stage. Survival data were obtained by telephone interview for 80 of the 83 patients at the last follow-up.

\section{Immunohistochemistry}

We used a tissue microarray (TMA) technique to reduce the number of slides and reduce bias. Selected blocks from tumor and non-tumor parenchyma were marked for TMA sampling. The tumor areas, which were punched out using $5 \mathrm{~mm}$ cores, were chosen based on how clearly the tumor area appeared and the absence of hemorrhage, necrosis, or traces of tissue processing. Cores were re-embedded in a TMA mold capable of accommodating 20 cores per block (Quick-ray, Seoul, Korea). The $5.0 \mu \mathrm{m}$ formalin-fixed, paraffinembedded tissue sections on the TMA slides obtained from each representative paraffin block were subjected to immunostaining using antibodies against AdipoR1 and AdipoR2 (Phoenix Pharmaceuticals, Burlingame, CA, USA).

Tissue array sections were deparaffinized with xylene and then rehydrated through graded alcohol solutions. Antigen retrieval consisted of boiling in Tris-EDTA buffer ( $\mathrm{pH} 9.0$ ) three times for 5 minutes each at $100^{\circ} \mathrm{C}$ in a microwave oven, and then cooling for 20 minutes at room temperature. Endogenous peroxidase activity was blocked with $3 \%$ hydrogen peroxide treatment for 15 minutes. The slides were washed in Tris-buffered saline (TBS, ScyTek, Logan, UT, USA) followed by primary antibody incubation at a 1:300 dilution for anti-adipoR1 and a 1:600 dilution for anti-adipoR2 for 2 to 3 hours at room temperature in a humidified incubator. After washing with TBS, the slides were incubated with dextran-coupled peroxidase and secondary antibody for 40 minutes in a humidified incubator, washed in TBS, incubated with substrate chromogen solution (3,3 diaminobezidine; TA125-HDX, LabVision, Thermo Scientific, Fremont City, CA, USA) for 8 to 10 minutes, and then rinsed with distilled water. The slides were counterstained with Meyer's hematoxylin (HMM999, Scytek Laboratories, Logan, UT, USA) and coverslipped for microscopic analysis.

The positive reaction of AdipoR1 and AdipoR2 antibodies was classified into one of four grades $(0,1+, 2+$ and $3+)$ based on the presence of brown granular staining intensity precipitates within the cytoplasm as well as the percentage of tumor cells that showed a positive reaction. Expression was scored as 0 if no cancer cells were positive or if $1-9 \%$ of tumor cells showed a positive reaction; $1+$ if stain- 
Table 1. Classification of immunohistochemical stain according to distribution and intensity of stain.

\begin{tabular}{ccc}
\hline Grade & Distribution & Intensity \\
\hline 0 & $0-10 \%$ & Negative \\
1 & $10-25 \%$ & Weak positive \\
2 & $26-50 \%$ & Moderate positive \\
3 & $>50 \%$ & Strong positive \\
\hline
\end{tabular}

\begin{tabular}{ccccc}
\hline \multirow{2}{*}{ Intensity } & \multicolumn{4}{c}{ Distribution } \\
\cline { 2 - 5 } & 0 & 1 & 2 & 3 \\
\hline 0 & $0(-)$ & $0(-)$ & $0(-)$ & $0(-)$ \\
1 & $0(-)$ & $1(1+)$ & $2(1+)$ & $3(2+)$ \\
2 & $0(-)$ & $2(1+)$ & $4(2+)$ & $6(3+)$ \\
3 & $0(-)$ & $3(2+)$ & $6(3+)$ & $9(3+)$ \\
\hline
\end{tabular}

ing showed weak intensity in $10-50 \%$ of tumor cells or moderate intensity in $10-25 \%$ of tumor cells; $2+$ if staining showed weak intensity in more than $50 \%$ of tumor cells, moderate intensity in $26-50 \%$ of tumor cells, or strong intensity in $10-25 \%$ of tumor cells; and $3+$ if staining showed moderate or strong intensity in more than $25 \%$ of tumor cells (Table 1). For statistical analyses, 0 and $1+$ were considered to be a negative stain and $2+$ and $3+$ to be a positive stain.

\section{Real-time polymerase chain reaction (PCR) analysis}

For the all procedures, the specimen was delivered for dissection and sampling as soon as it was removed from the patient. Eight to ten small pieces of fresh tissue were then collected from tumor and non-tumor areas of each of the 29 lung samples and stored in a tissue bank. The total RNA was extracted from fresh NSCLC tissues using the RNeasy Plus Mini kit, and reverse transcribed using QuantiTect reverse transcription reagents (Qiagen, Hilden, Germany) according to the manufacturer's instructions. cDNA (12.5 ng) was amplified using the TaqMan Gene Expression system (Applied Biosystems, Foster City, CA, USA), specific primers, and a FAM-tagged probe set (Applied Biosystems, Foster City, CA, USA). The thermal cycling protocol was 2 minutes at $50^{\circ} \mathrm{C}$ and 10 minutes at $95^{\circ} \mathrm{C}$, followed by 40 cycles at $95^{\circ} \mathrm{C}$ for 15 seconds and $60^{\circ} \mathrm{C}$ for 1 minute. Thermal cycling, fluorescence detection, and data analysis were performed on an ABI PRISM 7900 Sequence Detector using the software provided by the manufacturer. To create standard curves for AdipoR1 and AdipoR2, total RNA from human fat tissue was amplified in the same manner. GAPDH (glyceraldehyde 3-phosphate dehydrogenase) was used as an endogenous control.

\section{Statistical analysis}

For the continuous variables, data was presented as means \pm standard deviation. For AdipoR1 and AdipoR2 with abnormal distribution, data was presented as median (interquartile range) values. The categorical variables were presented as percentage (\%). The chisquared $\left(\chi^{2}\right)$ test was used to compare the immunohistochemical score and other clinicopathologic parameters. Students' $t$-tests and the Mann-Whitney $U$ test were used to compare mRNA levels of the adiponectin receptors in cancer and normal tissues by real-time PCR. Kaplan-Meier, Cox-regression, and log-rank tests were used to analyze the survival data and to compare these data between groups.
PASW software, version 18.0 (SPSS Inc., Chicago, IL, USA) was used for all statistical analyses. A $p$-value of $<0.05$ was considered statistically significant.

\section{Ethics statement}

This study was performed after obtaining approval from the Institutional Ethics Committee of Yonsei University, Wonju College of Medicine, Wonju, South Korea (IEC No. 2011-32) and is in compliance with the Helsinki Declaration.

\section{Results}

\section{Clinicopathological characteristics}

This study included 62 males and 21 females aged 41 to 89 years old (mean age, 66.5 years). The BMI of the patients was between $17.8-30.7 \mathrm{~kg} / \mathrm{m}^{2}\left(23.6 \pm 3.2 \mathrm{~kg} / \mathrm{m}^{2}\right)$. According to their treatment history, no patients in the current study were treated with TZD agents. Pathologic T-stage was evaluated according to tumor size and pleural invasion. The presence of pulmonary lymph node metastasis, smoker's bronchiolitis, and emphysematous changes were evaluated microscopically. The clinicopathological characteristics of the patients are summarized in Table 2.

\section{Immunohistochemical expression of adiponectin receptors}

Expression of AdipoR1 and AdipoR2 was detected in non-neoplastic lung epithelial cells (pneumocytes and bronchiolar mucosa) (Fig. 1A and B). Immunohistochemical staining for AdipoR1 was positive in 31 of 83 cases (37.3\%) in NSCLC tissues, whereas for AdipoR2 it was positive in 69 of 83 cases $(83.1 \%$, Fig. $1 \mathrm{C}$ to $\mathrm{F}$ and Table 3$)$. The immunohistochemical expression for AdipoR1 and AdipoR2 was not observed in most of the patients with squamous cell carcinoma (AdipoR1: 31/42, $p=0.04$ and AdipoR2: $21 / 41, p=0.77$, Table 3). Moreover, a significantly lower immunohistochemical expression for AdipoR1 was observed in NSCLC patients with a current smoking history than patients without a smoking history ( $p=0.003$, Table 3). The NSCLC cases with a higher T-stage showed lower immunohistochemical expression for AdipoR2 (T1: 90.9\%, T2: 83.6\%, T3: 50\%, $p=0.05$, Table 3).

\section{The $m R N A$ expression of adiponectin receptors using real- time PCR}

The mRNA levels of AdipoR1 and AdipoR2 were significantly lower in tumor tissue than matched normal tissue (AdipoR1: 0.76 (0.34-2.04), normal: 2.53 (1.82-3.35), AdipoR2: 1.03 (0.40-5.15), normal: 3.30 (2.30-5.87), $p<$ 0.050 ). Furthermore, the mRNA expression levels of AdipoR1 and AdipoR2 were significantly lower in NSCLC tissues (both subtypes: adenocarcinoma and squamous cell carcinoma) than non-neoplastic lung tissues (Fig. 2).

When the mRNA expression levels of AdiopR1 and AdipoR2 in NSCLC tissues were compared with clinicopathological parameters, we found that the mRNA level of AdipoR2 was significantly lower in cases with smoker's bronchiolitis ( $p=0.01)$, emphysema $(p=0.03)$, and squa- 
Table 2. Clinicopathological characteristics of patients with non-small cell lung carcinoma.

\begin{tabular}{lc}
\hline \multicolumn{1}{c}{ Parameters } & Mean (range), number (\%) \\
\hline Age (years) & $66.5(41-89)$ \\
Sex & $62(74.7)$ \\
Male & $21(25.3)$ \\
Female & $23.6(17.8-30.7)$ \\
BMI $^{*}\left(\mathrm{~kg} / \mathrm{m}^{2}\right)$ & \\
Subtype & $41(49.4)$ \\
Adenocarcinoma & $42(50.6)$ \\
Squamous cell carcinoma & \\
T-stage & $22(26.5)$ \\
$\mathrm{T}_{1}$ & $55(66.3)$ \\
$\mathrm{T}_{2}$ & $6(7.2)$ \\
$\mathrm{T}_{3}$ & \\
Smoking history & $29(34.9)$ \\
Current smoker & $15(18.1)$ \\
Non-smoker & $29(34.9)$ \\
Ex-smoker &
\end{tabular}

*BMI, body mass index

mous cell carcinoma $(p=0.05)$. In contrast, AdipoR1 mRNA was lower in cases with lymph node metastasis than those without ( $p=0.05$, Table 4$)$.

\section{Survival analysis}

We analyzed overall survival based on the expression of AdipoR1 and AdipoR2 protein and mRNAs. Follow-up survival data was available for 80 of the 83 patients. The length of the follow-up periods ranged from 1 month to 82 months, with the median length being 27 months. At the last follow-up, 33 of the 80 patients had died of disease (15 from adenocarcinoma, 18 from squamous cell carcinoma) and 47 were alive ( 26 from adenocarcinoma, 21 from squamous cell carcinoma). AdipoR1 protein was not expressed in 26 of the 33 patients who had died of disease (10 out of 15 adenocarcinoma cases, 16 out of 18 squamous cell carcinoma cases). In contrast, AdipoR2 was not expressed in 6 out of 33 patients who had died of disease ( 2 out of 15 adenocarcinoma cases, 4 out of 18 squamous cell carcinoma cases). Real-time PCR analysis results for AdipoR1 revealed lower mRNA expression of these receptors in patients who died of disease than patients who were still living at the last follow-up. The median mRNA expression level for AdipoR1 in patients who had died of disease was 0.57 (0.34-1.29), while it was $1.11(0.18-2.04)$ for the patients that were still living. The mRNA expression level of AdipoR2 in patients who had died of disease was 1.14 (0.57-2.33), while it was $1.01(0.40-5.15)$ for patients who were still living. Patients with a lower expression of AdipoR1 mRNA and protein had a lower overall survival than patients with a higher expression of these two receptors. Analysis of the Kaplan-Meier survival curves, which displayed the negative and positive expressions after logrank testing, found the results to be statistically insignificant (AdipoR1: log-rank test by immunohistochemistry; $p$ value $=0.074$, log-rank test by real-time PCR; $p$ value $=0.265$ and AdipoR2: log-rank test by immunohistochemistry; $p$ value $=0.285$, log-rank test by real-time PCR; $p$ value $=$ 0.327, Fig. 3).

\section{Discussion}

The association between adiponectin and the expression of its receptors in various diseases has attracted great interest in the oncology and endocrinology fields. Serum levels of adiponectin have been evaluated in different types of malignancies related to increased body weight and/or insulin resistance, such as colorectal (Wei et al. 2005), prostate (Michalakis et al. 2007), breast (Tworoger et al. 2007), endometrial (Petridou et al. 2003; Cust et al. 2007), and renal carcinomas (Spyridopoulos et al. 2007). Low circulating levels of adiponectin have been shown to be a potential risk factor for the malignancies mentioned above. Interestingly, a recent study in mice on stomach cancer as a non-obesity-related malignancy demonstrated that adiponectin administration reduced gastric cancer growth and peritoneal metastasis (Ishikawa et al. 2007). These findings support the hypothesis that adiponectin may play a role in carcinogenesis independent of obesity or insulin resistance.

Petridou et al. (2007) showed that adiponectin receptors are expressed in lung cancer tissue, and that advanced lung carcinoma cases have lower serum adiponectin levels. However, these authors did not detect expression of AdipoR1 and AdipoR2 in normal lung epithelium, nor did they evaluate the correlation between the expression of adiponectin receptors in lung carcinoma tissue and other clinicopathologic parameters through survival analysis. In our study, protein expression of AdipoR1 and AdipoR2 was detected in normal lung parenchyma (bronchial mucosa and pneumocytes), unlike the findings of Petridou and his team who performed immunohistochemical analysis of 122 NSCLCs and normal lung epithelium (Petridou et al. 2007). The discrepancy between their study and ours may be due to different assay conditions, such as different staining methods or antibodies used for immunostaining. The mRNA expression levels of AdipoR1 and AdipoR2 in non- 


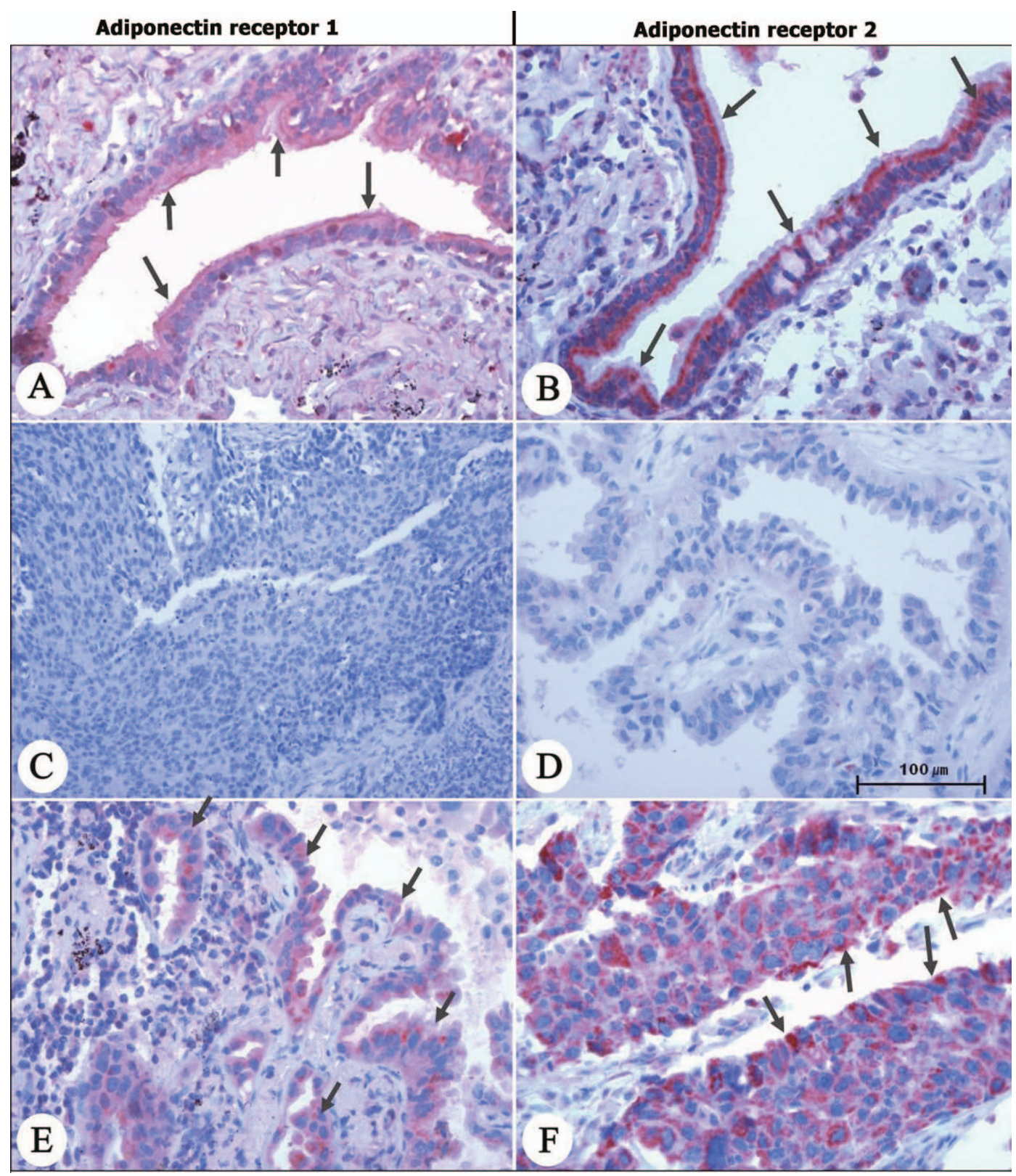

Fig. 1. Immunohistochemical staining of neoplastic and non-neoplastic lung parenchyma for AdipoR1 and AdipoR2. Expression of AdipoR1 and AdipoR2 is detected in non-neoplastic lung epithelial cells (A and B, respectively), expression of AdipoR1 in adenocarcinoma $(\mathrm{E}, 2+)$ and AdipoR2 in squamous cell carcinoma $(\mathrm{F}, 3+)$ and negative immunohistochemical expression of AdipoR1 and AdipoR2 in squamous cell carcinoma $(\mathrm{C}, 0)$ and adenocarcinoma $(\mathrm{D}, 1+)$ (Arrow; positive staining).

neoplastic lung tissue support our immunohistochemical findings that adiponectin receptors are expressed in normal lung epithelium. But due to the unavailability of banked blood, we were not able to compare these findings with the serum level of adiponectin.

In our study, we found that AdipoR1 and AdipoR2 were expressed at lower levels in NSCLC tissues than normal lung tissues based on real-time PCR and immunohistochemical analyses. In addition, we demonstrated that NSCLC cases with higher T-stage revealed lower immunohistochemical expression for AdipoR2. These findings could support the hypothesis that adiponectin inhibits lung cancer progression, but other factors like BMI, nutrition habits, alcohol consumption, smoking, inflammatory disease, and hormonal changes could also be related to changes in AdipoR1 and AdipoR2 (de Oliveira et al. 2012). A high expression of AdipoR1 and AdipoR2 in NSCLC tissue may facilitate the anti-carcinogenic effects of adiponectin, while a low expression of adiponectin receptors may promote NSCLC growth by protecting against the effects of adiponectin. Based on these results, loss of AdipoR1 and AdipoR2 expression appear to be correlated with the pro- 
Table 3. Association between protein expression of adiponectin receptors and clinicopathological parameters.

\begin{tabular}{|c|c|c|c|c|c|}
\hline \multirow{2}{*}{ Parameters } & \multicolumn{2}{|c|}{ AdipoR1 } & \multicolumn{2}{|c|}{ AdipoR2 } & \multirow{2}{*}{ Tota } \\
\hline & Positive cases $(\%)$ & $p$ value & Positive cases $(\%)$ & $p$ value & \\
\hline Age & & 0.320 & & 0.140 & 83 \\
\hline Sex & & 0.606 & & 0.104 & 83 \\
\hline Male & $22(35.5)$ & & $49(79.0)$ & & 62 \\
\hline Female & $9(42.9)$ & & $20(95.2)$ & & 21 \\
\hline $\operatorname{BMI}^{*}\left(\mathrm{~kg} / \mathrm{m}^{2}\right)$ & & 0.249 & & 0.557 & 83 \\
\hline Subtypes & & 0.042 & & 0.771 & 83 \\
\hline Adenocarcinoma & $20(48.8)$ & & $35(85.4)$ & & 41 \\
\hline Squamous cell carcinoma & $11(26.2)$ & & $34(81.0)$ & & 42 \\
\hline T-stage & & 0.178 & & 0.050 & 83 \\
\hline $\mathrm{T}_{1}$ & $12(54.5)$ & & $20(90.9)$ & & 22 \\
\hline $\mathrm{T}_{2}$ & $17(30.9)$ & & $46(83.6)$ & & 55 \\
\hline $\mathrm{T}_{3}$ & $2(33.3)$ & & $3(50.0)$ & & 6 \\
\hline Smoking history & & 0.003 & & 1.000 & 73 \\
\hline Current smoker & $4(13.8)$ & & $24(82.8)$ & & 29 \\
\hline Non-smoker & $5(33.3)$ & & $13(86.7)$ & & 15 \\
\hline Ex-smoker & $16(55.2)$ & & $24(82.8)$ & & 29 \\
\hline Stage of alcoholism & & 0.548 & & 0.622 & 61 \\
\hline Non-drinker & $10(37.0)$ & & $25(92.6)$ & & 27 \\
\hline Social drinker & $10(34.5)$ & & $24(82.8)$ & & 29 \\
\hline Daily drinker & $3(60.0)$ & & $4(80.0)$ & & 5 \\
\hline Lymph node metastasis & & 0.440 & & 0.161 & 83 \\
\hline Present & $10(34.5)$ & & $22(75.9)$ & & 29 \\
\hline Absent & $21(38.9)$ & & $47(87.0)$ & & 54 \\
\hline Smoker's bronchiolitis & & 1.000 & & 0.761 & 83 \\
\hline Present & $20(37.7)$ & & $45(84.9)$ & & 53 \\
\hline Absent & $11(36.7)$ & & $24(80.0)$ & & 30 \\
\hline Emphysema & & 0.454 & & 1.000 & 83 \\
\hline Present & $7(29.2)$ & & $20(83.3)$ & & 24 \\
\hline Absent & $24(40.7)$ & & $49(83.1)$ & & 59 \\
\hline
\end{tabular}

*BMI, body mass index
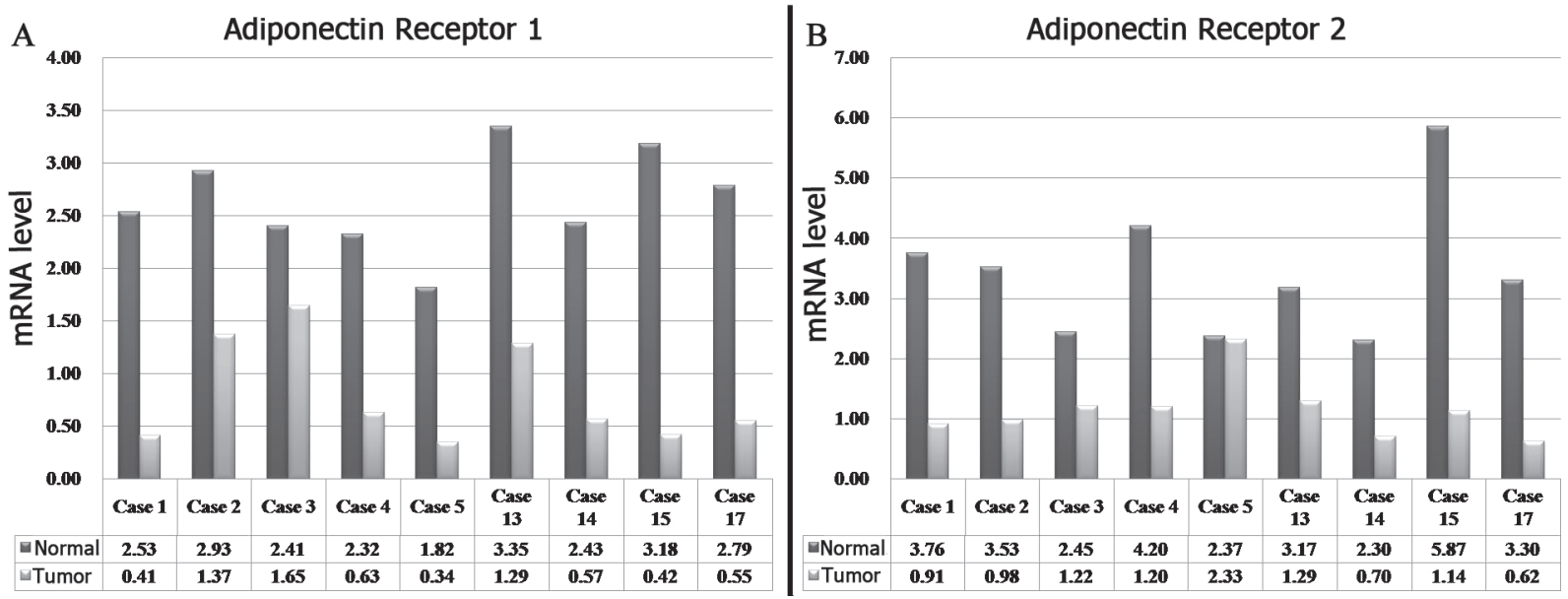

Fig. 2. The mRNA expression level of adiponectin receptors by real-time PCR in neoplastic and non-neoplastic lung tissues. Paired real-time PCR analyses showed lower mRNA levels of AdipoR1 (A) and AdipoR2 (B) in NSCLC tissues compared to matched non-neoplastic tissues (cases 1 to 5: adenocarcinoma; cases 13 to 15 and case 17: squamous cell carcinoma). 
Table 4. Association between mRNA expression levels of adiponectin receptors and clinicopathological parameters.

\begin{tabular}{|c|c|c|c|c|c|}
\hline \multirow{2}{*}{ Parameters } & \multicolumn{2}{|c|}{ AdipoR1 } & \multicolumn{2}{|c|}{ AdipoR2 } & \multirow{2}{*}{ Total } \\
\hline & Median (range) & $p$ value & Median (range) & $p$ value & \\
\hline Sex & & 0.34 & & 0.30 & 29 \\
\hline Male & $0.75(0.18-1.65)$ & & $1.02(0.40-5.15)$ & & 24 \\
\hline Female & $1.29(0.43-2.04)$ & & $1.20(0.93-1.72)$ & & 5 \\
\hline $\mathrm{BMI}^{*}$ & & 0.60 & & 0.09 & 29 \\
\hline $\operatorname{High}\left(\geq 25 \mathrm{~kg} / \mathrm{m}^{2}\right)$ & $0.74(0.18-2.04)$ & & $0.93(0.40-5.15)$ & & 14 \\
\hline Low $\left(<25 \mathrm{~kg} / \mathrm{m}^{2}\right)$ & $1.18(0.34-1.65)$ & & $1.09(0.70-2.46)$ & & 15 \\
\hline Subtypes & & 0.14 & & 0.05 & 29 \\
\hline Adenocarcinoma & $1.27(0.34-2.04)$ & & $1.18(0.57-5.15)$ & & 12 \\
\hline Squamous cell carcinoma & $0.68(0.18-1.65)$ & & $0.96(0.40-2.75)$ & & 17 \\
\hline T-stage & & 0.28 & & 1.00 & 29 \\
\hline $\operatorname{High}\left(\mathrm{T}_{3}+\mathrm{T}_{4}\right)$ & $0.96(0.18-2.04)$ & & $1.03(0.40-5.15)$ & & 25 \\
\hline Low $\left(\mathrm{T}_{1}+\mathrm{T}_{2}\right)$ & $0.59(0.34-1.29)$ & & $1.00(0.53-2.33)$ & & 4 \\
\hline Smoking History & & 0.65 & & 0.51 & 29 \\
\hline Smoker & $1.00(0.18-1.65)$ & & $1.03(0.40-5.15)$ & & 20 \\
\hline Non-smoker & $0.63(0.42-2.04)$ & & $0.98(0.49-1.72)$ & & 9 \\
\hline Stage of alcoholism & & 0.37 & & 0.41 & \\
\hline Non-drinker & $1.16(0.43-2.04)$ & & $1.04(0.53-2.75)$ & & 9 \\
\hline Drinker & $0.85(0.41-1.65)$ & & $1.02(0.40-2.46)$ & & 12 \\
\hline Lymph node metastasis & & 0.054 & & 0.98 & 29 \\
\hline Present & $0.55(0.18-1.52)$ & & $1.01(0.41-5.15)$ & & 10 \\
\hline Absent & $1.05(0.41-2.04)$ & & $1.03(0.40-2.75)$ & & 19 \\
\hline Smoker's bronchiolitis & & 1.000 & & 0.014 & 29 \\
\hline Present & $0.75(0.18-2.04)$ & & $0.97(0.40-2.75)$ & & 22 \\
\hline Absent & $1.26(0.34-1.52)$ & & $1.29(0.91-5.15)$ & & 7 \\
\hline Emphysema & & 0.31 & & 0.032 & 29 \\
\hline Present & $1.06(0.18-1.65)$ & & $0.74(0.41-1.29)$ & & 12 \\
\hline Absent & $0.68(0.34-2.04)$ & & $1.14(0.40-5.15)$ & & 17 \\
\hline
\end{tabular}

* BMI, body mass index

gression of human NSCLC.

As the T-stage progresses, the tumor mass grows and lymph node metastasis spreads (Lee et al. 2008). Real-time PCR analysis revealed a significantly lower mRNA expression level of AdipoR2 in the cases with lymph node metastasis. However, immunohistochemical analysis revealed no significant correlation between adiponectin receptor expression and lymph node metastasis.

Serum levels of adiponectin have been found to have an inverse correlation with smoking (Abbasi et al. 2006; Takefuji et al. 2007; Otsuka et al. 2009; Sull et al. 2009; Kawamoto et al. 2010). We therefore assessed whether expression of adiponectin receptors was associated with the smoking status of the patients. AdipoR1 protein expression was lower in current smokers than ex-smokers and nonsmokers. AdipoR1 was expressed at lower levels in cases of squamous cell carcinoma, a well known smoking-related malignancy, than in adenocarcinoma. Furthermore, the mRNA expression level of AdipoR2 was lower in cases with smoker's bronchiolitis and cases of squamous cell car- cinoma than in cases without smoking history and cases of adenocarcinoma, respectively. These findings suggest that smoking may reduce the tissue expression of adiponectin receptors, particularly AdipoR1 in NSCLC, in addition to its effects on reducing plasma levels of adiponectin (Takefuji et al. 2007; Otsuka et al. 2009; Kawamoto et al. 2010).

Survival analysis found no statistical significance for AdipoR1 and AdipoR2 either by immunohistochemistry or real-time PCR, although, the log-rank test revealed that patients with higher AdipoR1 mRNA and protein expression had relatively longer survival. The statistical insignificance of our survival analysis could be due to the small sample size.

As mentioned earlier, obesity plays a major role in regulating the level of circulating adiponectin. Therefore, BMI as an obesity index may be correlated with adiponectin receptor expression in tissues. However, we did not find any association between BMI and expression of adiponectin receptors in NSCLC tissues. This suggests that the expres- 

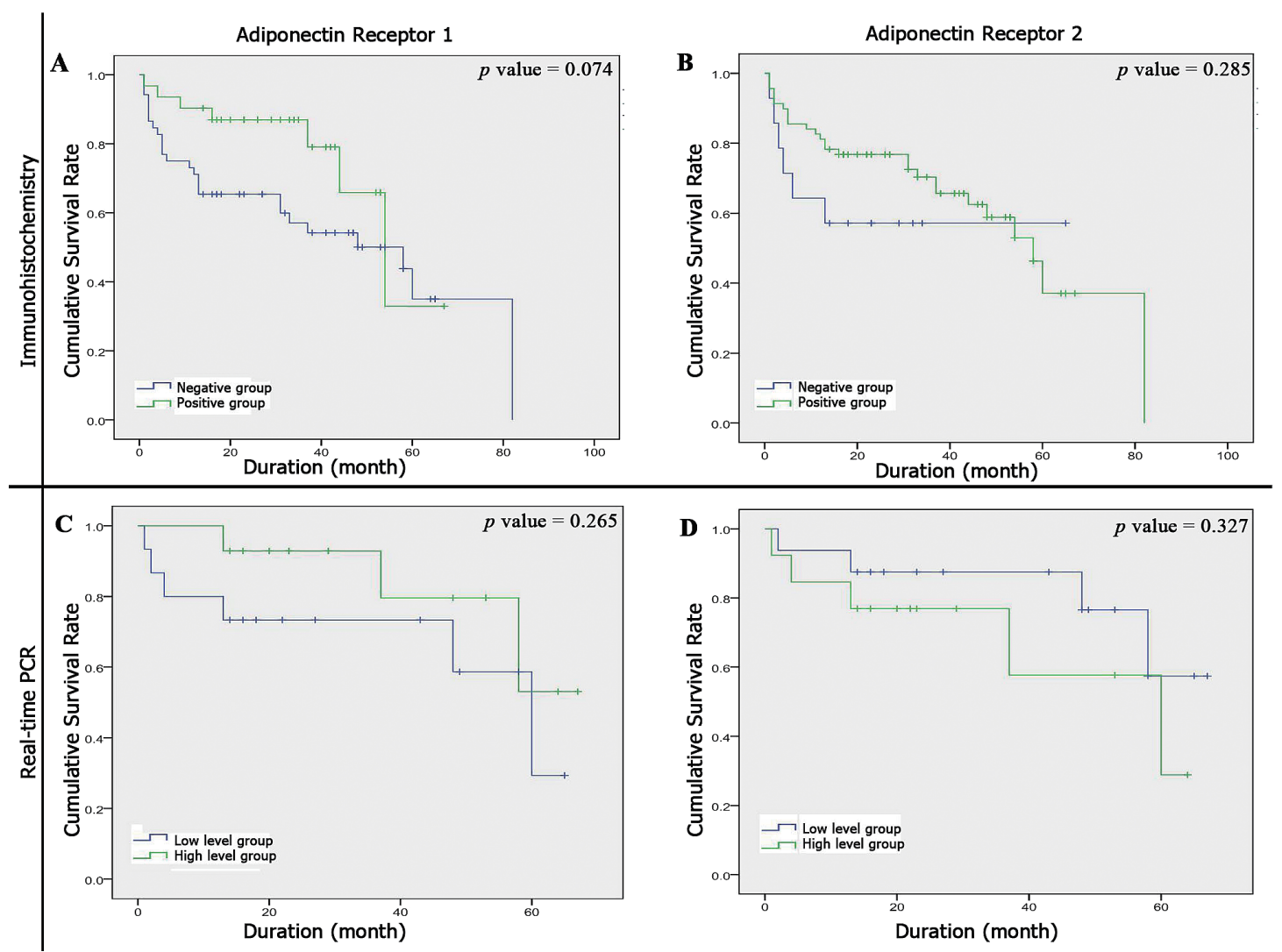

Fig. 3. The correlation of overall survival with immunohistochemical and mRNA expression of AdipoR1 and AdipoR2 in NSCLC patients.

Based on log-rank test, the Kaplan-Meier curves reveal that patients with AdipoR1, protein (A) and mRNA (C) expression have longer overall survival, although it is not statistically significant. However, there is no correlation between overall survival and AdipoR2 protein (B) and mRNA (D) expression.

sion of adiponectin receptors may be controlled not only by the fat tissue and circulating adiponectin levels, but also by other factors such as smoking and cancer cell characteristics, including tumor differentiation and NSCLC subtype. Real-time PCR analysis confirmed lower levels of both AdipoR1 and AdipoR2 mRNAs in squamous cell carcinomas and adenocarcinomas compared to normal tissues.

In lung cancer tissues the prediction of overall protein expression is not possible based on average mRNA abundance (Chen et al. 2002). Our study also reveals that, when compared with other clinicopathological parameters, there is relative discrimination between protein expression by immunostaining and mRNA expression by real-time PCR. It suggests that the abundance of adiponectin can be further enhanced due to other transcriptional mechanisms in lung carcinomas (Chen et al. 2002). Both adiponectin receptors show higher expression of protein and mRNA levels in normal lung tissue than NSCLC, as judged by immunostaining or real-time PCR analysis. A slightly different expression between these two receptors according to various clinicopathological parameters can be expressed because AdipoR1 and AdipoR2 show only $66.7 \%$ structural homology (Kadowaki et al. 2006). To the best of our knowledge, ours is the first study to show a definite association between adi- ponectin receptor expression and a malignancy unrelated to obesity or insulin resistance.

In conclusion, in our data, the inverse correlation between AdipoR2 expression and T-stage suggests that AdipoR2 has the possibility of being involved in cancer growth suppression in NSCLCs, while AdipoR1 may have prognostic significance. Based on our results, we suggest that changes in the expression of adiponectin and its receptors are intimately related to the progression of NSCLCs and that these changes may have prognostic and therapeutic implications. Moreover, smoking could be related to a decrease in adiponectin levels and the expression of adiponectin receptors in target tissue, thereby favoring carcinogenesis.

A large number of cases should be analyzed and compared with the serum level of adiponectin in future studies to confirm our findings and to determine the implications of adiponectin and its receptors as novel targets for inhibition of NSCLC growth.

\section{Acknowledgments}

This work was supported by a research grant from Yonsei University Wonju College of Medicine (YUWCM-12-65). 


\section{Conflict of Interest}

The authors declare no conflict of interest.

\section{References}

Abbasi, F., Farin, H.M., Lamendola, C., McLaughlin, T., Schwartz, E.A., Reaven, G.M. \& Reaven, P.D. (2006) The relationship between plasma adiponectin concentration and insulin resistance is altered in smokers. J. Clin. Endocrinol. Metab., 91, 5002-5007.

Barresi, V., Tuccari, G. \& Barresi, G. (2009) Adiponectin immunohistochemical expression in colorectal cancer and its correlation with histological grade and tumour microvessel density. Pathology, 41, 533-538.

Benaitreau, D., Dieudonne, M.N., Dos Santos, E., Leneveu, M.C., Mazancourt, P. \& Pecquery, R. (2009) Antiproliferative effects of adiponectin on human trophoblastic cell lines JEG-3 and BeWo. Biol. Reprod., 80, 1107-1114.

Blanquicett, C., Roman, J. \& Hart, C.M. (2008) Thiazolidinediones as anti-cancer agents. Cancer Ther, 6, 25-34.

Bub, J.D., Miyazaki, T. \& Iwamoto, Y. (2006) Adiponectin as a growth inhibitor in prostate cancer cells. Biochem. Biophys. Res. Commun., 340, 1158-1166.

Byeon, J.S., Jeong, J.Y., Kim, M.J., Lee, S.M., Nam, W.H., Myung, S.J., Kim, J.G., Yang, S.K., Kim, J.H. \& Suh, D.J. (2010) Adiponectin and adiponectin receptor in relation to colorectal cancer progression. Int. J. Cancer, 127, 2758-2767.

Chandran, M., Phillips, S.A., Ciaraldi, T. \& Henry, R.R. (2003) Adiponectin: more than just another fat cell hormone? Diabetes Care, 26, 2442-2450.

Chen, G., Gharib, T.G., Huang, C.C., Taylor, J.M., Misek, D.E., Kardia, S.L., Giordano, T.J., Iannettoni, M.D., Orringer, M.B., Hanash, S.M. \& Beer, D.G. (2002) Discordant protein and mRNA expression in lung adenocarcinomas. Mol. Cell. Proteomics, 1, 304-313.

Cong, L., Gasser, J., Zhao, J., Yang, B., Li, F. \& Zhao, A.Z. (2007) Human adiponectin inhibits cell growth and induces apoptosis in human endometrial carcinoma cells, HEC-1-A and RL95 2. Endocr. Relat. Cancer, 14, 713-720.

Cust, A.E., Kaaks, R., Friedenreich, C., Bonnet, F., Laville, M., Lukanova, A., Rinaldi, S., Dossus, L., Slimani, N., Lundin, E., Tjonneland, A., Olsen, A., Overvad, K., Clavel-Chapelon, F., Mesrine, S., Joulin, V., Linseisen, J., Rohrmann, S., Pischon, T., Boeing, H., Trichopoulos, D., Trichopoulou, A., Benetou, V., Palli, D., Berrino, F., Tumino, R., Sacerdote, C., Mattiello, A., Quiros, J.R., Mendez, M.A., Sanchez, M.J., Larranaga, N., Tormo, M.J., Ardanaz, E., Bueno-de-Mesquita, H.B., Peeters, P.H., van, Gils, C.H., Khaw, K.T., Bingham, S., Allen, N., Key, T., Jenab, M. \& Riboli, E. (2007) Plasma adiponectin levels and endometrial cancer risk in pre- and postmenopausal women. J. Clin. Endocrinol. Metab., 92, 255-263.

de Oliveira, C., de Mattos, A.B., Silva, C.B., Mota, J.F. \& Zemdegs, J.C. (2012) Nutritional and hormonal modulation of adiponectin and its receptors adipoR1 and adipoR2. Vitam. Horm., 90, 57-94.

Dieudonne, M.N., Bussiere, M., Dos Santos, E., Leneveu, M.C., Giudicelli, Y. \& Pecquery, R. (2006) Adiponectin mediates antiproliferative and apoptotic responses in human MCF7 breast cancer cells. Biochem. Biophys. Res. Commun., 345, 271-279.

Dos Santos, E., Benaitreau, D., Dieudonne, M.N., Leneveu, M.C., Serazin, V., Giudicelli, Y. \& Pecquery, R. (2008) Adiponectin mediates an antiproliferative response in human MDA-MB 231 breast cancer cells. Oncol. Rep., 20, 971-977.

Gonullu, G., Kahraman, H., Bedir, A., Bektas, A. \& Yucel, I. (2010) Association between adiponectin, resistin, insulin resistance, and colorectal tumors. Int. J. Colorectal. Dis., 25,
205-212.

Govindarajan, R., Ratnasinghe, L., Simmons, D.L., Siegel, E.R., Midathada, M.V., Kim, L., Kim, P.J., Owens, R.J. \& Lang, N.P. (2007) Thiazolidinediones and the risk of lung, prostate, and colon cancer in patients with diabetes. J. Clin. Oncol., 25, 1476-1481.

Hamano, M., Kamada, Y., Kiso, S., Furuta, K., Kizu, T., Chatani, N., Egawa, M., Takemura, T., Ezaki, H., Yoshida, Y., Watabe, K., Hamasaki, T., Umeda, M., Furubayashi, A., Kinoshita, K., Kishida, O., Fujimoto, T., Yamada, A., Tsukamoto, Y., Tsutsui, S., Takehara, T., Hayashi, N. \& Matsuzawa, Y. (2012) Adiponectin negatively correlates with alcoholic and non-alcoholic liver dysfunction: health check-up study of Japanese men. Hepatol. Res., (published online).

Ishikawa, M., Kitayama, J., Yamauchi, T., Kadowaki, T., Maki, T., Miyato, H., Yamashita, H. \& Nagawa, H. (2007) Adiponectin inhibits the growth and peritoneal metastasis of gastric cancer through its specific membrane receptors adipoR1 and adipoR2. Cancer Sci., 98, 1120-1127.

Jemal, A., Siegel, R., Ward, E., Murray, T., Xu, J., Smigal, C. \& Thun, M.J. (2006) Cancer statistics, 2006. CA. Cancer J. Clin., 56, 106-130.

Kadowaki, T., Yamauchi, T., Kubota, N., Hara, K., Ueki, K. \& Tobe, K. (2006) Adiponectin and adiponectin receptors in insulin resistance, diabetes, and the metabolic syndrome. $J$. Clin. Invest., 116, 1784-1792.

Kang, J.H., Lee, Y.Y., Yu, B.Y., Yang, B.S., Cho, K.H., Yoon, D.K. \& Roh, Y.K. (2005) Adiponectin induces growth arrest and apoptosis of MDA-MB-231 breast cancer cell. Arch. Pharm. Res., 28, 1263-1269.

Kawamoto, R., Tabara, Y., Kohara, K., Miki, T., Ohtsuka, N., Kusunoki, T. \& Abe, M. (2010) Smoking status is associated with serum high molecular adiponectin levels in communitydwelling Japanese men. J. Atheroscler. Thromb., 17, 423-430.

Kelesidis, I., Kelesidis, T. \& Mantzoros, C.S. (2006) Adiponectin and cancer: a systematic review. Br. J. Cancer, 94, 12211225 .

Lee, J.G., Lee, C.Y., Bae, M.K., Park, I.K., Kim, D.J., Kim, K.D. \& Chung, K.Y. (2008) Validity of international association for the study of lung cancer proposals for the revision of $\mathrm{N}$ descriptors in lung cancer. J. Thorac. Oncol., 3, 1421-1426.

Makita, S., Abiko, A., Nagai, M., Yonezawa, S., Koshiyama, M., Ohta, M. \& Nakamura, M. (2012) Influence of daily alcohol consumption on serum adiponectin levels in men. Metabolism, (published online).

Mantzoros, C., Petridou, E., Dessypris, N., Chavelas, C., Dalamaga, M., Alexe, D.M., Papadiamantis, Y., Markopoulos, C., Spanos, E., Chrousos, G. \& Trichopoulos, D. (2004) Adiponectin and breast cancer risk. J. Clin. Endocrinol. Metab., 89, 1102-1107.

Michalakis, K., Williams, C.J., Mitsiades, N., Blakeman, J., Balafouta-Tselenis, S., Giannopoulos, A. \& Mantzoros, C.S. (2007) Serum adiponectin concentrations and tissue expression of adiponectin receptors are reduced in patients with prostate cancer: a case control study. Cancer Epidemiol. Biomarkers Prev., 16, 308-313.

Miller, M., Cho, J.Y., Pham, A., Ramsdell, J. \& Broide, D.H. (2009) Adiponectin and functional adiponectin receptor 1 are expressed by airway epithelial cells in chronic obstructive pulmonary disease. J. Immunol., 182, 684-691.

Mistry, T., Digby, J.E., Chen, J., Desai, K.M. \& Randeva, H.S. (2006) The regulation of adiponectin receptors in human prostate cancer cell lines. Biochem. Biophys. Res. Commun., 348, 832-838.

Miyoshi, Y., Funahashi, T., Kihara, S., Taguchi, T., Tamaki, Y., Matsuzawa, Y. \& Noguchi, S. (2003) Association of serum adiponectin levels with breast cancer risk. Clin. Cancer Res., 9, 5699-5704.

Molica, S., Digiesi, G., Vacca, A., Mirabelli, R., Todoerti, K., 
Battaglia, C., Morabito, F., Neri, A. \& Ribatti, D. (2009) Does adiponectin act as an antiangiogenic factor in B-cell chronic lymphocytic leukemia? Adv. Hematol., 2009, 287974.

Otsuka, F., Kojima, S., Maruyoshi, H., Matsuzawa, Y., Funahashi, T., Kaikita, K., Sugiyama, S., Kimura, K., Umemura, S. \& Ogawa, H. (2009) Smoking cessation is associated with increased plasma adiponectin levels in men. J. Cardiol., 53, 219-225.

Petridou, E., Mantzoros, C., Dessypris, N., Koukoulomatis, P., Addy, C., Voulgaris, Z., Chrousos, G. \& Trichopoulos, D. (2003) Plasma adiponectin concentrations in relation to endometrial cancer: a case-control study in Greece. J. Clin. Endocrinol. Metab., 88, 993-997.

Petridou, E.T., Mitsiades, N., Gialamas, S., Angelopoulos, M., Skalkidou, A., Dessypris, N., Hsi, A., Lazaris, N., Polyzos, A., Syrigos, C., Brennan, A.M., Tseleni-Balafouta, S. \& Mantzoros, C.S. (2007) Circulating adiponectin levels and expression of adiponectin receptors in relation to lung cancer: two case-control studies. Oncology, 73, 261-269.

Sierksma, A., Patel, H., Ouchi, N., Kihara, S., Funahashi, T., Heine, R.J., Grobbee, D.E., Kluft, C. \& Hendriks, H.F. (2004) Effect of moderate alcohol consumption on adiponectin, tumor necrosis factor-alpha, and insulin sensitivity. Diabetes Care, 27, 184-189.

Spyridopoulos, T.N., Petridou, E.T., Skalkidou, A., Dessypris, N., Chrousos, G.P. \& Mantzoros, C.S. (2007) Low adiponectin levels are associated with renal cell carcinoma: a case-control study. Int. J. Cancer, 120, 1573-1578.
Sull, J.W., Kim, H.J., Yun, J.E., Park, E.J., Kim, G. \& Jee, S.H. (2009) Serum adiponectin is associated with smoking status in healthy Korean men. Endocr. J., 56, 73-78.

Takefuji, S., Yatsuya, H., Tamakoshi, K., Otsuka, R., Wada, K., Matsushita, K., Sugiura, K., Hotta, Y., Mitsuhashi, H., Oiso, Y. \& Toyoshima, H. (2007) Smoking status and adiponectin in healthy Japanese men and women. Prev. Med., 45, 471-475.

Tworoger, S.S., Eliassen, A.H., Kelesidis, T., Colditz, G.A., Willett, W.C., Mantzoros, C.S. \& Hankinson, S.E. (2007) Plasma adiponectin concentrations and risk of incident breast cancer. J. Clin. Endocrinol. Metab., 92, 1510-1516.

Wei, E.K., Giovannucci, E., Fuchs, C.S., Willett, W.C. \& Mantzoros, C.S. (2005) Low plasma adiponectin levels and risk of colorectal cancer in men: a prospective study. J. Natl. Cancer Inst., 97, 1688-1694.

Yoneda, K., Tomimoto, A., Endo, H., Iida, H., Sugiyama, M., Takahashi, H., Mawatari, H., Nozaki, Y., Fujita, K., Yoneda, M., Inamori, M., Nakajima, N., Wada, K., Nagashima, Y., Nakagama, H., Uozaki, H., Fukayama, M. \& Nakajima, A. (2008) Expression of adiponectin receptors, adipoR1 and adipoR2, in normal colon epithelium and colon cancer tissue. Oncol. Rep., 20, 479-483.

Yoshizaki, T., Motomura, W., Tanno, S., Kumei, S., Yoshizaki, Y. \& Okumura, T. (2010) Thiazolidinediones enhance vascular endothelial growth factor expression and induce cell growth inhibition in non-small-cell lung cancer cells. J. Exp. Clin. Cancer Res., 29, 22. 